\title{
PROJECT BASED LEARNING APPLIED TO BACHELOR'S DEGREE IN ENERGY ENGINEERING
}

\author{
I. Marton ${ }^{1}$, S. Gallardo², J.F. Villanueva², A. Sánchez' ${ }^{1}$, S. Carlos ${ }^{2}$ \\ ${ }^{1}$ Universitat Politècnica de València, Dpto. de Estadística e Investigación Operativa \\ Aplicadas y Calidad (SPAIN) \\ ${ }^{2}$ Universitat Politècnica de València, Dpto. de Ingeniería Química y Nuclear (SPAIN)
}

\begin{abstract}
The standards and guidelines for quality assurance in the European Higher Education Area (EHEA) lay down that one of the keys to combining learners' knowledge and skills is the implementation of new student-centred active competence-based teaching methodologies. One of the most widely used and effective of these methodologies is Project Based Learning (PBL). Although a significant number of these initiatives have been carried out in recent decades, in most cases they are limited to implementing individual subjects with few applications to the degree curriculum. In this context, the main goal of this work was to develop a project-based learning system in two subjects of the Bachelor's Degree in Energy Engineering at the Universitat Politècnica de València. The problem is analysed from a practical point of view, using theoretical concepts in the subject of "Statistics" and their subsequent implementation in the subject "Energy and Sustainable Development". The developed methodology is described, together with the coordination between these two subjects, the results achieved and the initial conclusions obtained.
\end{abstract}

Keywords: Project based learning (PBL), Energy Engineering Degree, Wind farm.

\section{INTRODUCTION}

The European Higher Education Area's (EHEA) directives on competence learning include considerations on both student-centred learning and active learning [1], in which Project Based Learning (PBL) plays a special role. PBL is a practical teaching method in which the aim is for students to carry out practical research and problem solving in projects by applying the theoretical concepts they have already learned. This method is highly versatile and can be adapted to individual cases as regards its scope, the different disciplines involved and the professional standard required.

Including PBL in the learning process has been shown to be useful for teaching specific and transversal competences together in the subject or subjects to which it has been applied and also to prepare students for their professional careers [2]. Some of the studies carried out propose methods for evaluating these competences as well as evaluating teachers and students. [3] proposes a procedure for evaluating competences in a University of Vigo Master's Degree by students and lecturers in accordance with the well-known published rules. In Ref. [4] also proposes rules for the same purpose and gives the results of their application to an experimental group in a degree course at the University of Alicante. He concluded that it had positive effects on the students' academic performance and motivation.

Before applying the method, the lecturer must draw up a schedule with the activities to be carried out by the students both in and out of the classroom. Evaluations are then used to determine the extent to which the teaching objectives have been achieved in terms of the students' newly acquired skills and competences. This new method requires the lecturer to perform a different role; he must now act as the students' guide and companion in the learning process [5].

Although a number of important initiatives have been put into practice in recent decades, most of them are confined to implementing single subjects and do not have a marked effect on the course syllabi.

The present authors detected shortcomings in the basic concepts of several subjects that hindered the development of certain competences in the Energy Engineering (EE) degree course at the Universitat Politècnica de València (UPV). In this context, the Chemical and Nuclear Engineering Department and the Department of Applied Statistics and Operational Research on Quality worked together to identify weaknesses, threats, strengths and opportunities in EE subjects and found that there was room for improvement in the teaching methods used in the first-year subject "Statistics" and second-year 
subject "Sustainable Energy and Development". To remedy this situation, it was proposed to optimise the teaching resources by promoting synergies between the two subjects.

The problem became clear when we tried to apply statistical methods to problems associated with the generation of energy. In the year 2017/18 we determined that the difficulty of following the problems proposed and solved in class was particularly pronounced in the production of wind energy, since the problems were based on the statistical Weibull distribution, which characterises the behaviour of the frequency of wind velocity. It was also found that students had by this time become especially interested in subjects related to renewable energy. Joining these two facts together, we identified a weakness (deficient theoretical and technical foundations) and a strength (attraction for renewable energy) in the two subjects mentioned above.

To sum up, vertical coordination helped us to detect this weakness and strength and to establish a joint teaching-learning strategy to be used as the main approach to both subjects.

The general aim of this work was to design project-based activities, develop methods and define the appropriate learning-centred evaluation techniques based on projects to be carried out in the subject of "Energy and Sustainable Development" while reinforcing the use of concepts learned in the subject of "Statistics" in the Energy Engineering degree course. The study was part of the University of Valencia's 2-year (2018-20) Educational Innovation and Improvement Project and was applied to the Energy Engineering degree course. As this project is still in its first year, only the methods used and results obtained during this period will be described here.

The specific aims were as follows:

- To design activities for the subject "Statistics" that could be transversally integrated into the learning objectives of the subject "Energy and Sustainable Development".

- To observe the results obtained from the implementation of the method.

The implementation and context of the innovation, the method itself, the first results obtained, and the initial conclusions are described in the following subsections.

\section{DEVELOPMENT OF THE INNOVATION}

The subjects in which project-based learning were to be introduced were the first year "Statistics" and the second year "Energy and Sustainable Development" in the EE degree course. Both subjects are compulsory and thus have to be taken by all the students on the course. The mean size of the groups has been fairly constant during recent years and has stayed around 75 to 80 students.

In recent years it had been seen that the students had experienced certain problems when applying the theoretical concepts learned in first-year Statistics to the practical problems they were given to solve in the second year. This implied the loss of opportunities to use the synergy between the different subjects for more effective teaching of certain competences. In this context, the main objective was to develop a project that would integrate specific and transversal competences in these subjects so that the students could apply theoretical concepts to practical cases. When the students use statistical tools they are developing two different skills: that of calculating together with practical work on an energy project.

As mentioned above, the project is still in its first year, so that it is still being applied to first-year students only. "Statistics" is worth 0.8 computer practice credits, divided into four practical 2-hour sessions. The innovations are being implemented in the sessions in which statistics are applied to energy-related problem solving. These sessions will later be used to apply statistics as a decision making tool.

As choosing the right subject for the project was one of the problems that appeared in the first meetings, the first step consisted of selecting subjects for the practical sessions. This took the form of giving a questionnaire to the 86 EE first-year 2018/19 students to find out their preferences. The results obtained are shown in Fig. 1 and 2 . The first gives the interest shown by the students in the different types of renewable or non-renewable energy, while the second gives their interest in carrying out a project related to the different energy sources. 


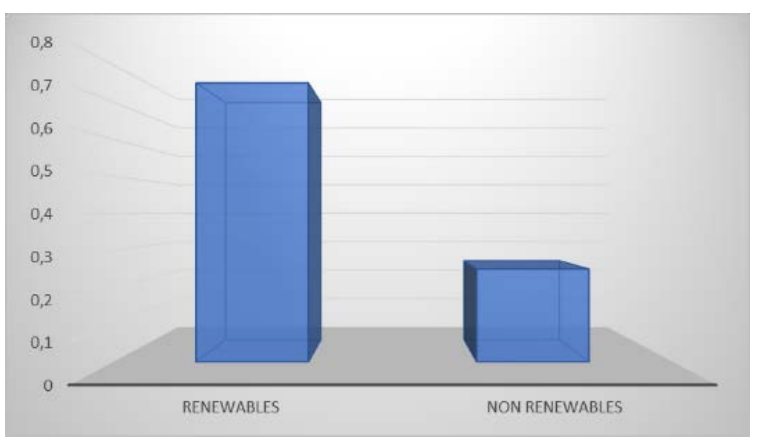

Figure 1 Interest in types of energy.

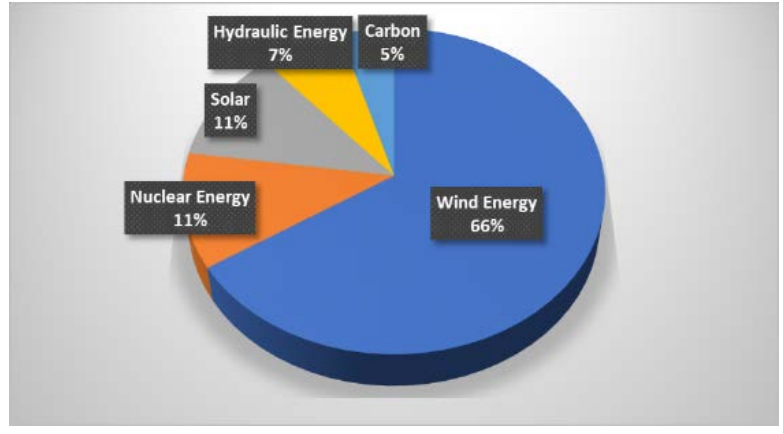

Figure. 2 Interest in the different subjects for a project.

After analysing the results of the survey, the following conclusions were reached:

- $75 \%$ of the students surveyed were interested in renewable energy sources.

- $81 \%$ considered theoretical statistics to be a very useful decision-making tool able to predict electricity consumption, although they still did not have a practical perspective.

- $66 \%$ would like to carry out a project related to wind-generated energy during their academic career.

In this context, using the results of the survey together with the lecturers' previous knowledge of the subject "Sustainable Energy and Development", it was decided to carry out the project in the field of wind energy so that the students would be motivated by using real data applied to their professional field and thus promote their active participation in the classroom.

After deciding on the project's core subject and meetings with the lecturers of both subjects, the following practical sessions were proposed for "Statistics":

- Practice 1: Descriptive statistical analysis of wind speed and the power generated by a wind turbine.

- Practice 2: Qualitative study of a wind turbine power curve.

- Practice 3: Characterization of the Weibull distribution of wind speeds from real data acquired from a wind farm.

- Practice 4: Comparison of different locations for a wind farm using statistical inference.

The first activity-planning stage involved the maximum coordination from the beginning between the two subjects as regards the use of the same nomenclature and the same projects. The classroom resources were also optimized as regards both content and hardware in order to improve the synergy and integration of basic statistical concepts in the second-year subject.

So far, no explicit work has been done on the learning involved in the second-year subject projects, although a certain amount has been done on the method used in the practice sessions, after which a highly positive feedback was received from the students.

\section{RESULTS}

The results obtained from this project are given below, including firstly the direct results of the intersubject coordination (unification and clarification of concepts, planned activities, indicator tablets and rules generated) and secondly the results in terms of the project's impact on the first-year students' classroom performance.

\subsection{Direct results of coordination}

The results of the meetings on coordination and planning in the first stage of the innovation were among the most important, since they allowed the lecturers to achieve a basic understanding by unifying and clarifying concepts, besides fixing the students' boundaries and requirements in both years. The meetings were used to plan the project and lay the foundations for the different competences to be considered in both subjects. 
Activities were also carried out in "Statistics" in order to improve the inter-subject synergies. A descriptive card was created with the structure of the fragment shown in Table 1 for each of the planned activities. For example, in the second-year subject "Energy and Sustainable Development", among other factors, the students had to study wind speed to determine the energy available for the wind farm to generate power, because when they came to study the subject in the second year it was important that they should understand and be able to characterise the wind speed probability density function, for which Practice 3 was designed (see results in Table 1).

Table 1. Example of activity card (fragment).

\begin{tabular}{|c|c|}
\hline Activity & $\begin{array}{l}\text { Characterisation of Weibull distribution of wind speed based on information from a } \\
\text { wind farm's data capture system. }\end{array}$ \\
\hline Subject & "Statistics" \\
\hline $\begin{array}{l}\text { Transversal } \\
\text { Competences }\end{array}$ & $\begin{array}{l}\text { (01) Understanding and integration. } \\
\text { (02) Application and practical thinking. } \\
\text { (11) Permanent Learning. }\end{array}$ \\
\hline Description & $\begin{array}{l}\text { When projecting a wind farm it is essential to be able to describe wind speed variations in } \\
\text { order to optimise turbine design and operations and keep costs to a minimum. } \\
\text { The learning results aimed for are the following: } \\
\text { - Understand that the wind's energy content continually varies because wind speed } \\
\text { constantly fluctuates. } \\
\text { - Draw up a wind speed frequency model. } \\
\text { - Characterise the Weibull probability distribution function with shape and scale } \\
\text { parameters. } \\
\text { - Calculate wind probability and use it to calculate wind turbine energy. } \\
\text { - Estimate percentage time in which turbine is inoperative due to insufficient or } \\
\text { excessive wind speed, respectively. } \\
\text { This activity is carried out in groups of three. Each group is given a historic data card from a } \\
\text { Spanish wind farm's data collection system to work with. } \\
\text { Students will be given a practice guide plus a card with the information to be used in the } \\
\text { practice and will be required to answer the questions in the guide in a Word document, } \\
\text { including any explanations considered necessary plus screenshots of the results obtained } \\
\text { on Stratgraphics software. } \\
\text { The questions may include the following: } \\
\text { - Establish the shape and scale parameters that characterise the Weibull distribution } \\
\text { obtained. } \\
\text { - Define the Weibull probability density function for wind speed. } \\
\text { - Work out the probabilities from the distribution function. } \\
\text { - Apply the Weibull distribution function to calculate wind turbine power capacity. } \\
\text { Power Curve. }\end{array}$ \\
\hline
\end{tabular}

Rules were also drawn up to evaluate the acquired level of different transversal competences. To date, this has only been done for "Statistics" as regards individual levels and the topics dealt with.

\subsection{Classroom results}

The second type of results (impact on students) was evaluated by measuring the effects on the students' work after applying the innovative teaching method.

In this case the results obtained are still not entirely clear, since the method included in the new teaching project is still in its first year and no feedback has yet been obtained from the students. However, they appear to be more receptive in class and to better assimilate the theoretical concepts, which they can now associate with real problems. They are also taking more active roles in the learning process and are better motivated, while communications with the lecturers have improved. It 
should be emphasised that all the evidence will be justified in the future when the results of the teaching surveys are analysed. The lecturers have drawn up a Satisfaction Questionnaire to be answered at the end of the semester with the aim of gauging the acceptance level among the students of the method used in the practice sessions. The questionnaire consists of "informal" questions, such as the following:

- Do you think these activities have been useful?

- Have you changed your ideas on the use of "Statistics" in the energy field?

- Which activity/practice did you like most?

\section{CONCLUSIONS}

This work was carried out within the framework of a teaching project whose aim is to draw up methods and define appropriate evaluation project-based learning-centred techniques in "Energy and Sustainable Development" while reinforcing the use of concepts learned in "Statistics" in the Energy Engineering degree course. As the project is still in its first year, only the initial approach used in firstyear Statistics is described.

Although not a great deal of feedback has yet been received from the students, they have actively participated in the method and their initial impressions are highly positive. At this early stage the students have achieved the learning objectives with higher grades than those previously attained with traditional lab practice methods. At the same time the method has facilitated developing and evaluating both specific subject competences and transversal competences such as understanding, integration, application and practical thinking.

In the second half of the project the aim is to go deeper into Energy and Sustainable Development and obtain general conclusions.

Since we are working with students from different years with different knowledge levels, immediate results cannot be expected, as at least three years will be required to obtain reliable feedback from the students who have completed subjects dealt with in this teaching innovation.

\section{ACKNOWLEDGEMENTS}

This study was carried out within the framework of the Educational Innovation and Improvement Project (PIME in Spanish) Year 2018/19 "Coordination of transversal competences in key subjects in the Energy Engineering Degree (Reference B16) of the Vice Chancellor for Studies, Quality and Accreditation of the Polytechnic University of Valencia.

\section{REFERENCES}

[1] GARCIA, J., PEREZ, J. (2018) Aprendizaje basado en proyectos: método para el diseño de Actividades. Revista Tecnología, Ciencia e Innovación, CEF, núm. 10 (mayo-agosto 2018, pp. 37-63

[2] HUFF, J. L., ZOLTOWSKI, C. B. AND OAKES, W. C. (2016), Preparing Engineers for the Workplace through Service Learning: Perceptions of EPICS Alumni. Journal of Engineering Education. 105,43-69.

[3] CUIÑAS I., MARIÑO-ESPIÑEIRA P., FERNANDEZ-IGLESIAS M., CAEIRO, M., COSTAMONTENEGRO E., DIAZ-OTERO F. (2016). Evaluación de competencias con metodologías de aprendizaje basado en proyectos. Congreso INRED 2016

[4] GUERRERO, E., CALERO, J. (2013) "El aprendizaje basado en proyectos como base metodológica en el grado de Educación Social" Educación social. Revista de Intervención Socioeducativa, 53, p. 73-91

[5] MARIMOM, M. (2013). Colaborar para aprender. En G. Bautista y A. Escofet (Comp.). Enseñar y aprender en la universidad. Claves y retos para la mejora (pp. 47-72). 